\title{
A EDUCAÇÃo AMBIENTAL E A ÁGUA NA PORÇÃo DA REGIÃO DAS ILHAS DE BELÉM COMO ARTIFÍCIO E FOMENTO AO ENSINO DA GEOGRAFIA
}

\author{
THE ENVIRONMENTAL EDUCATION LINKED TO THE USE AND MANAGEMENT OF \\ WATER IN THE INSULAR REGION OF BELEM AS A STRATEGY TO TEACHING \\ GEOGRAPHY
}

\section{LA EDUCACIÓN AMBIENTAL ALIADA AL USO Y GESTIÓN DEL AGUA EN LA PARTE INSULAR DE BELÉN COMO UNA ESTRATEGIA E INCENTIVO EN LA ENSEÑANZA DE GEOGRAFÍA}

\section{Resumo}

O presente estudo de caso é fruto de um projeto de intervenção que assumiu um caráter de uma pesquisa descritiva, desenvolvida a partir das atividades realizadas em parceria pelos grupos de pesquisa "Saberes Geográficos: diálogo entre Ensino, Pesquisa e Extensão" (IFPa) e o "Grupo de Pesquisa em Geografia das Águas da Amazônia" (GGAM/UFPA), nos semestres consecutivos do período de 2017à 2018, junto à disciplina Educação Ambiental, ministradas para duas turmas de $4^{o}$ semestre, de Licenciatura em Geografia e Pedagogia do IFPA Campus Belém. A pesquisa tem como objetivo saber de que forma os discentes destes cursos compreendem no interior da disciplina de Educação Ambiental a temática "água" sob um enfoque Ambiental dotado de potencial para o ensino da Geografia, a partir de sua própria realidade local. O resultado revelou o quanto a prática da "Pedagogia dos Projetos", aliado a ensino da Geografia e a Educação Ambiental, onde numa dada realidade tratou de estimular no sujeito a clara percepção do matrimônio teoria versus prática, presentes nos relatórios redigidos pelos alunos, bem como, a aplicação das teorias no objeto concreto visitado pelos alunos, os quais facilitaram a identificação $e$ compreensão de certos fenômenos, e processos sociais de modo que, perceberam e aplicaram satisfatoriamente os conceitos aprendidos em sala, em dada realidade.

Palavras-chave: Educação Ambiental. Ensino de Geografia. Representação Social. Recursos Hídricos.

\section{Abstract}

The present case study is result of an intervention project, which assumed a descriptive research form, from activities performed by the research groups "Geographical knowledges: a dialogue between teaching, researching and extension" (IFPA) and the "Amazonian Waters Geography Research Group" (GGAM/UFPA). The developed activities were on the consecutive semesters of the 2017 to 2018 period with the subject of Environmental Education, ministered to the classrooms from $4^{\text {th }}$ semester of Geography and Pedagogy at IFPA Campus Belém. We intended to know what the students from these courses understand as

\footnotetext{
${ }^{1}$ Geógrafa, mestranda do Programa de Pós-Graduação Interdisciplinar em Sociedade Ambiente e Qualidade de Vida PPGSAQ da Universidade Federal do Oeste do Pará - UFOPA. Colaboradora no grupo de pesquisa "Geografia das Águas da Amazônia". E-mail and trindade@yahoo.com.br

2 Professor da Universidade do Estado do Pará (UEPA) e da Secretaria Municipal de Educação em Belém (SEMEC). Email professormichelguedes@yahoo.com.br

${ }^{3}$ Professora do Instituto Federal do Instituto Federal de Educação, Ciência e Tecnologia do Pará e Doutoranda pela Universidade de São Paulo. E-mail shileytozi@yahoo.com.br
} 
"water" - under a focus in the Environment endowed of potential for the teaching of Geography from their own local reality - inside their discipline of Environmental Education. The result showed how the practice of the "Pedagogy of Projects", allied to the teaching of Geography and Environmental Education, in a certain reality, dealt with the stimulation of the subject to the clear perception of "theory" versus "practice", present in the reports written by the students. Just as the application of the Theories in the concrete object, in which the students have visited, facilitated the identification and comprehension of certain phenomena, social processes, in a way that they satisfactorily noticed and applied the apprehended concepts in class to given reality.

Keywords: Environmental Education. Teaching of Geography. Social Representation. Hydric Resources.

\section{Resumen}

El presente estudio de caso es el resultado de um proyecto de intervención con carácter de investigación descriptiva de las atividades en conjunto emprendidas por los grupos investigativos "Conocimientos geográficos: un diálogo entre enseñanza, investigación y extensión” (IFPA) y el Grupo de Investigaciónen "Geografía de las Aguas Amazónicas" (GGAM/UFPA). Las actividades se desarrollaronenlos semestres consecutivos del 2017 al 2018 com la asignatura de Educación Ambiental, impartidasen dos cursos del $4^{o}$ semestre de la Licenciatura em Geografía y Pedagogía del IFPA de Belém. La intención del estudio era aprender como los estudiantes de estos cursos comprenden dentro de laasignatura "Educación Ambiental" el tema "el Agua", bajo un enfoque ambiental con potencial para la enseñanza de la geografía desde supropiarealidad local. Los resultados revelaron como la práctica de la "Pedagogía de Proyectos", junto a la enseñanza de la geografía y la educación ambiental, en una determinada realidade intentó estimular al sujeto a la clara percepción de teoría versus práctica, presente em los informes redactados por los estudiantes, así como la aplicación de las teorias em el objeto concreto estudiados por los alumnos que facilitó la identificación y comprensión de ciertos fenómenos, los processos sociales, de forma que comprendieron y aplicaron satisfactoriamente los conceptos aprendidos enclase a una determinada realidad. Palabras clave: Educación Ambiental. Enseñanza de Geografía. Representación Social. Recursos Hídricos.

\section{INTRODUÇÃO}

O presente trabalho é fruto de uma ação de pesquisa, desenvolvido a partir das atividades realizadas pelos grupos de pesquisa SABERES GEOGRÁFICOS: DIÁLOGO ENTRE ENSINO, PESQUISA E EXTENSÃO (IFPA) e o Grupo de Pesquisa em Geografia das Águas da Amazônia (GGAM/UFPA), no período de 2017a 2018. O objetivo deste trabalho foi a demonstração do resultado de uma pesquisa aliado a prática de sala de aula, baseado na temática da Educação Ambiental (EA), associado à perspectivados recursos hídricos (RH's) e embasado no ensino de geografia.

Buscou-se neste trabalho estabelecer uma relação entre os saberes que perpassam pelo ensino de Geografia e Pedagogia inserindo-as numa abordagem da educação ambiental, seja pela leitura geográfica a partir dos seus conceitos de seus ramos, seja a geografia urbana e o seu debate do meio rural, o conceito de território e paisagem, bem como, um diálogo interdisciplinar atrelado ao fazer pedagógico, como um exercício de intervenção e da prática educativa na realidade, in loco, dialogando com os preceitos da educação ambiental enquanto eixo transversal que pode perpassar as duas ciências, seja, pelo debate da diferenciação entre desenvolvimento sustentável e sustentabilidade, o primeiro enquanto discurso e o segundo mais adequado a reflexão da representação social a partir dos sujeitos que habitam a ilha do Combú e que também exercem a educação ambiental, enquanto representação social. 
A pesquisa teve como procedimento metodológico a pesquisa bibliográfica, porém, assumiu um caráter de uma pesquisa descritiva, cuja forma se deu por meio de um estudo de caso junto a duas turmas de alunos de graduação, dos cursos de Licenciatura em Geografia e Pedagogia do $4^{\circ}$ semestre, do IFPA Campus Belém. Com a realização do trabalho de campo, onde permitiu a obtenção pela coleta de dados e, no fim, realizou-se a produção de um relatório (fruto extraído), utilizado como atividade avaliativa aos alunos.

O locus de realização do trabalho seu deu a partir da cidade de Belém do Pará, por meio de realização de Atividade de Campo destinado à porção insular do município de Belém, na chamada Ilha do Combú, umas das 39 ilhas que compõe o arquipélago integrante do município e também na porção rural do município adjacente, denominado Acará, distante a 25min de Belém, onde nas duas localidades o é por via fluvial.

A problemática do conjunto da pesquisa foi em buscarmos entender de que forma os discentes dos cursos de graduação de Licenciatura em Geografia e Pedagogia compreendem no interior das disciplinas a temática "água" sob um enfoque da Educação Ambiental, onde o tema é dotado de potencial para o ensino da Geografia, a partir de sua própria realidade local.

Portanto, o conjunto deste trabalho partiu das aplicações e produtos das inúmeras atividades desenvolvidas ao longo de disciplinas de EA, ministradas nos cursos superiores voltados para a formação de Licenciados em Geografia e Pedagogia para alunos do $4^{\circ}$ do IFPA Campus Belém, nos semestres e anos consecutivos de 2017 e 2018. Foram consideradas as matrizes e os ementários da disciplina EA para os dois cursos, bem como os PPC's (Projeto Pedagógico de Curso), os quais, a partir de um enfoque da ciência geográfica, pautou-se numa abordagem interdisciplinar associado à Pedagogia dos Projetos e uso da metodologia do trabalho de campo para obtenção global dos resultados.

A base teórica adotada para esse trabalho é a mesma aplicada nos planejamentos das aulas, bem como a mesma apresentada aos alunos para composição dos seus relatórios, pois a proposição das aulas era "desafiar" os sujeitos para a realização da relação teoria versus prática. Assim, optamos em trabalhar uma base teórica que envolvesse os vários temas adotados, aqui chamados de "Níveis Temáticos".

Na área do Ensino da Geografia, adotamos Straforini (2004),Paulo (2016),Cavalcanti (2005) e Castrogiovani (2000). Na área da dos Recursos Hídricos, foram adotadas Ribeiro(2008), Tozi (2009) e Bordalo (2016). No âmbito da Geografia foram utilizados Raffestin (1993) e Gonçalves(2015). No eixo da Educação Ambiental, Loureiro (2012), Onça(2012), Reigota(2010) e Santos (2009).

Em termos de Pedagogia de Projetos, optamos por Nogueira(2007) e na matriz Trabalho de Campo, baseada em Neves(2010), aqui devidamente agregado e, enquanto metodologia de ensino e estratégia para agregar a teoria versus prática, por meio de um fazer pedagógico, aplicado ao ensino de Geografia e, através da observação, a identificação dos fenômenos e processos teorizados em sala de aula e seu posterior entendimento, análise e aplicação como produto contribuinte no aprendizado do sujeito. 


\section{METODOLOGIA}

O presente trabalho teve como procedimento metodológico a pesquisa bibliográfica. Porém, assumiu um caráter de uma pesquisa descritiva, cujo procedimento metodológico se deu a partir do:

a) referencial bibliográfico com ênfase em Geografia e Pedagogia utilizados para planejamento inserido dentro de duas(02) disciplinas (Geografia da Amazônia e seu Ensino \& Educação Ambiental), ambos para turmas de pedagogia de $4^{\circ}$ semestre , em intervalos de 1 ano entre cada disciplina ministrada, onde, os ementários puderam ser cruzados e adequados a intenção macro da educação ambiental;

b) forma ministradas aulas teóricas presenciais dialogadas; c) foi realizada a orientação e confecção de um Projeto Ação direcionados para as duas (02) turmas envolvidas, sendo uma de Licenciatura em Pedagogia e outra Licenciatura em Geografia, com 35 (trinta e cinco) e 31 (trinta e um) alunos, respectivamente, que elaboram relatórios em grupo. Logo, toda a ação deste Projeto teve sua duração semestral inserida na disciplina de Educação Ambiental (EA), ministrada entre os anos de 2017 e 2018;

c) Foram realizados 02 trabalhos de campo, em momentos distintos com cada turma, onde, o produto fora;

d) a confecção de relatórios, de onde foi extraída a compreensão dos discentes.

Partindo da tema macro da "Educação Ambiental", enquanto disciplina ministrada e de concepções e variações conceituais devidamente adequadas aos ementários desta disciplina trabalhada nos dois cursos, o objetivo foi a realização de uma leitura e análise essencialmente geográfica, associando o tema "água" (RH's) como elo comum de abordagem face ao contexto local, vivido pelos discentes para a devida convergência para a temática da EA, esquematicamente apresentados na Fig.1

Fig.1 - Esquema das abordagens temáticas e conceituais trabalhadas

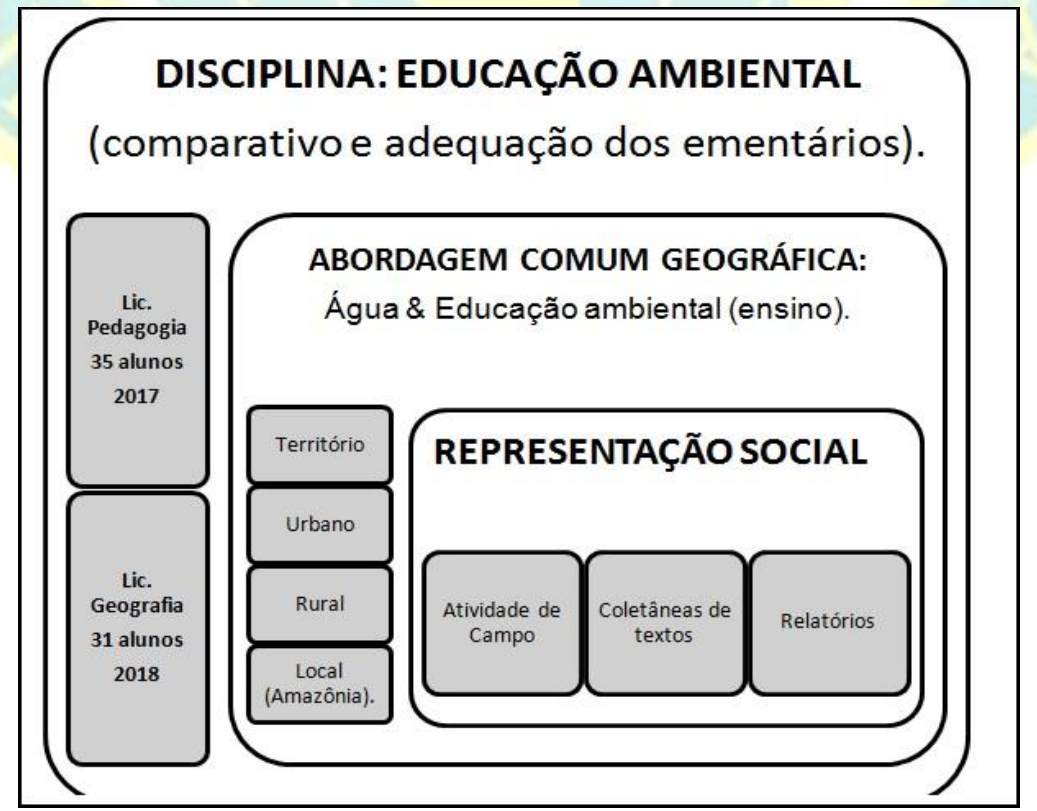




\section{RESULTADOS E DISCUSSÕES}

\section{A Pedagogia dos Projetos}

Considerando a prática cotidiana do professor em qualquer nível de ensino, desde a educação básica até o ensino superior, parte-se da ideia de que, todo Projeto de Intervenção Escolar, quer seja um Projeto de Extensão Universitária, não pode ser uma mera atenção à burocratização da Universidade ou da Escola.

Por essa razão, há tempos os chamados Projetos Temáticos (PT) viraram moda no ambiente acadêmico em geral. Assim, esse "modismo" tornou-se preocupante, quanto a sua implementação no ambiente escolar, uma vez que, estes PT's ainda são meramente ações desenvolvidas pela imposição das coordenações escolares aos professores, ofuscando o caráter estritamente dinâmico e criativo que envolve um projeto de intervenção desde a sua concepção, aplicação e resultados (NOGUEIRA, 2007, p. 11).

A prática da elaboração de projetos-ação revela-se preocupante, pois, poucos professores na educação básica trabalham efetivamente e adequadamente com o que denominamos apoiados em Nilbo Nogueira (2007) de Pedagogia dos Projetos e, muitas vezes, a formação acadêmica não prepara o suficiente os dissidentes para essa realidade.

\section{A Educação Ambiental enquanto Representação Social}

A principal linha de pensamento deste trabalho é a concepção de Educação Ambiental adotada por Marcos Reigota (2010).O caminho adotado por esse autor é uma abordagem reflexiva a partir do vários conceitos adotados para a compreensão da meio ambiente, desde o sentido do dicionário passado pelos vários ramos do conhecimento como Ecologia, Psicologia inclusive a Geografia, diga-se de passagem, segundo este autor trata como: "É ao mesmo tempo uma realidade científica, um tema de agitação, o objeto de um grande medo uma diversão, uma especulação". (PIERRE GEORGE 1982, p.18 apud REIGOTA, 2010, p.68).

Essa intenção do autor é pertinente, uma vez que leva o discente a refletir as várias acepções adota pela comunidade científica sobre o que venha ser meio ambiente, para posterior entendimento do que venha ser a Educação Ambiental propriamente dita. No percurso da obra, este autor faz uma indagação instigante:

“Meio Ambiente: conceito científico ou representação social?” (REIGOTA,2010,p.11). Assim, a partir dessa pergunta, fez-se necessário trabalhar com os alunos a noções de construção de um conceito.

Assim, os alunos foram provocados a essa reflexão sobre "o que seria um conceito?", o qual se realizou na intenção de descortinar o que venha a ser um conceito com base numa fração relevante do texto de LENCIONE $^{4}$ (2008), pois, nesta exposição da autora sobre "as sete premissas sobre um conceito" permite levar o discente aos caminhos de (re)construção de ideias cristalizadas, tal como, na Geografia o conceito de "natureza", por exemplo.

\footnotetext{
4 “Sete observações sobre conceitos in: Observações Sobre o Conceito de Cidade E Urbano” (2008, p. 24).
} 


\section{A educação ambental e a água na porção da região das ilhas de Belém como artíficio e}

fomento ao ensino de geografia

Ao obter esta leitura, a partir do entendimento da construção de "um conceito", provocando sujeito acadêmico, público deste trabalho, uma reflexão de que nenhuma ideia está absolutamente fechada, bem como o próprio caráter dinâmico de um conceito, o qual permite levá-lo a uma visão mais aberta quanto à realidade pesquisada para devida comparação entre a teoria e o objeto concreto, neste caso a realidade local, pois, mesmo Marcos Reigota (2010) afirma que um conceito científico são termos, entendidos e utilizados universalmente com tais.(REIGOTA, 2010,p.12).

A escolha da noção de meio ambiente enquanto Representação Social (RS) é tida como: "É o lugar determinado ou percebido, onde os elementos naturais e sociais estão em relação dinâmicas e em interação. Essas relações implicam processos de criação cultural e tecnológica e processos históricos e sociais e de transformação do meio natural construído" (REIGOTA, 2010, p.12).

Essa concepção se aproxima da Geografia, pois, conforme esquematicamente apresentado na Figura 2 e examinando centrifugamente é possível enxergar do ponto de vista temático a amplitude dessa abordagem e o tangenciar com a Geografia. Muito embora, não estejamos trabalhando a categoria geográfica Lugar, ainda assim, tanto Território quanto Paisagem se adeque à ideia de RS, haja vista que o Território em si, por estabelecer relações intrínsecas de poder, é fruto de práticas, comportamento se relações estabelecidas por um grupo de atores que, inclusive, se estabelecem noutra categoria geográfica, o chamado Espaço Geográfico que nos próprios dizeres do Geógrafo Claude Raffestin: "É essencial compreender bem que o espaço é anterior ao território". (Raffestin, 1993, p.144).

Convergindo, para o debate dos Recursos Hídricos (RH's), aquele em que a água é dotada de valor econômico (GUEDES, 2016, p.42), ou seja, a água, sendo vista enquanto mercadoria, encontra-se sujeita às leis do mercado de oferta e procura, sendo então dotada de precificação. Esse debate é pertinente, pelo lócus de realização desta prática, no caso a cidade Belém, inserida num contexto de Amazônia, portanto, o maior reservatório de água doce no estado líquido do planeta, e por ser Belém, uma cidade cercada por águas.

Haja vista que, a cidade de Belém, possui atualmente 14 (quatorze) Bacias Hidrográficas e, por meio de seu desenho urbano, é delimitada pelas águas. Estando banhada ao Sul pelo Rio Guamá (que na sua foz mede entre 1.360 e 2.000 m de largura) e a Norte pelo Furo do Maguari e a Oeste pela Baía do Guajará (possui em torno de 3 a $4 \mathrm{~km}$ de largura) e a leste pelo município de Ananindeua. Ainda, possuí uma porção continental, a cidade propriamente dita, e uma porção insular composta por 39 ilhas, pela qual, esta última assume feições rurais. Assim, as reflexões realizadas com os alunos perpassaram por subtemas como: gestão e gerenciamento das águas, abastecimento, bacias hidrográficas, apoiados em Tozi, (2009), Bordalo (2016) e Guedes (2016). 
Fig. 2: A amplitude do conceito de representação social aplicado á Geografia

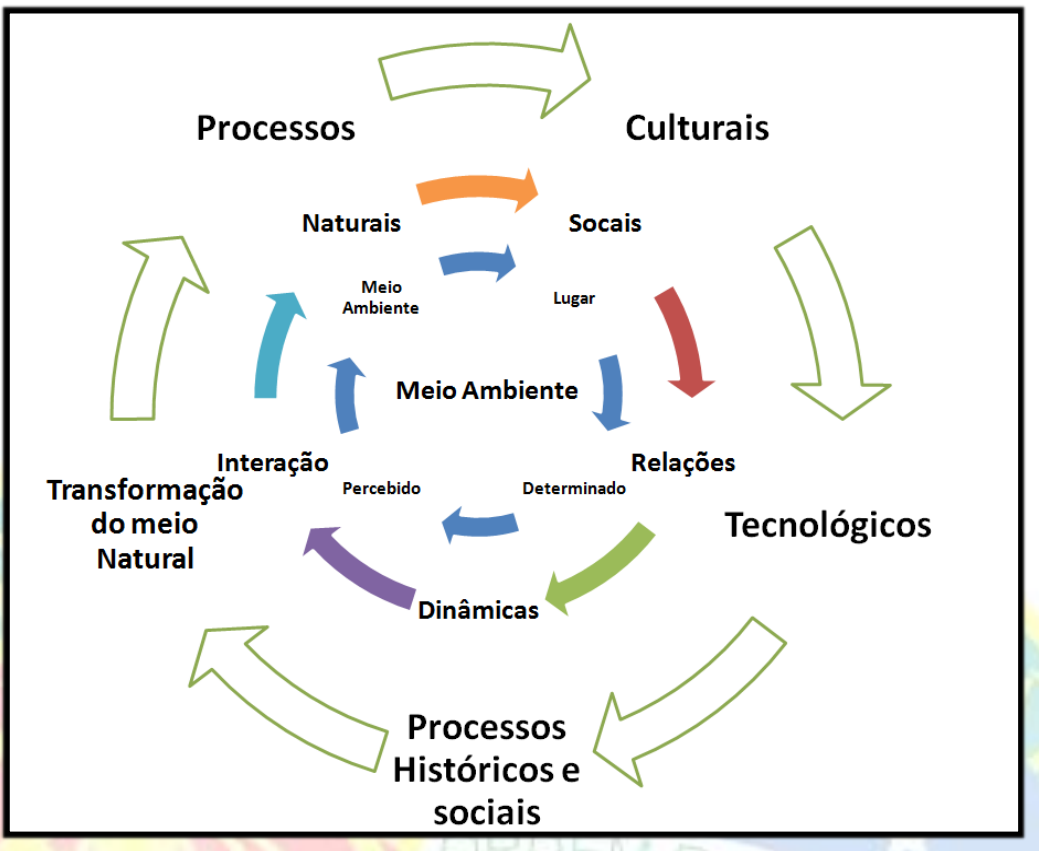

Nesse sentido, outra dimensão eminentemente geográfica é a isenção nesse debate dos conceitos de urbanização, uma vez que, realizar com os alunos um comparativo entre as duas realidades (rural e urbano), ou mesmo, apresentá-los ao espaço rural que passa a ser outra realidade desses sujeitos, provocando neles apercepção de uma nova perspectiva na realização de ações, voltada para refletir a própria EA em si. O contexto, pois, de ilhas (rural) se demonstrou muito significativo ao que o geógrafo Eidorfe Moreira (19121989) chamou de "espaço insular hídrico da capital". (MOREIRA, apud GUERRA, 2015, p.2) e, assim, o quadripé Educação Ambiental, Geografia, Representação Social e Recursos Hídricos apresentam-se como um encaixe apropriado na organização dos saberes e no desenvolvimento de uma prática educativa eficaz para trabalhar a Educação Ambiental, conforme esquematiza a Figura 3 e Figura 4: 
A educação ambental e a água na porção da região das ilhas de Belém como artíficio e fomento ao ensino de geografia

Fig. 30 quadripé eficaz para uma prática educativa eficaz. Fonte: o autor.

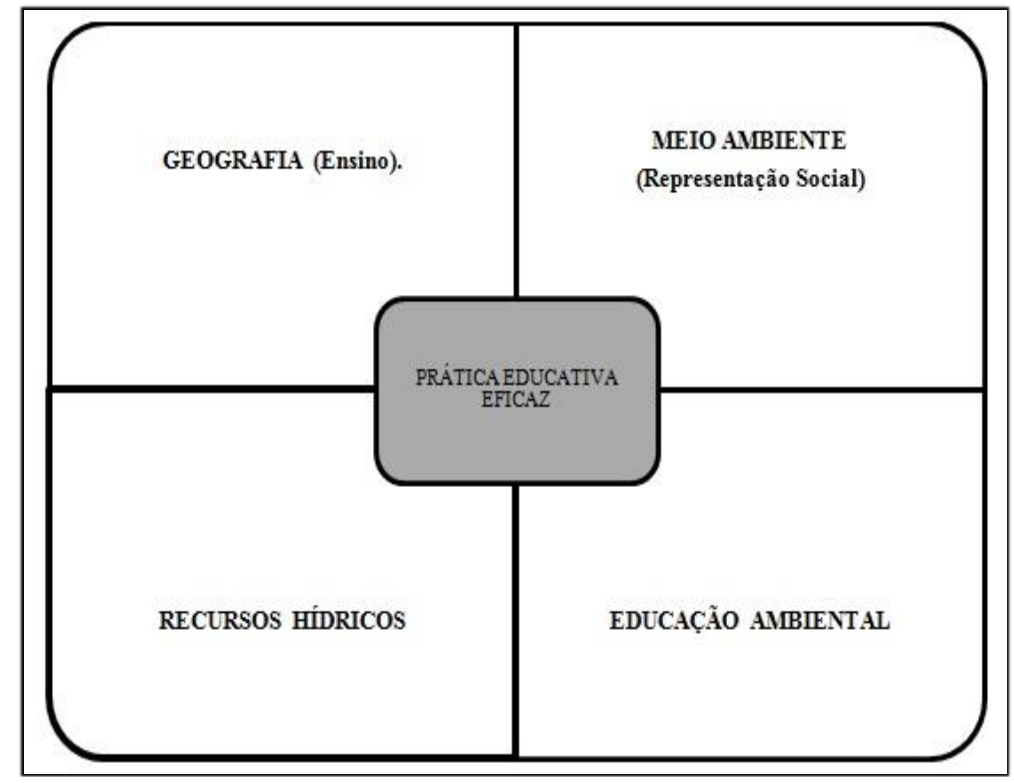

Mas afinal, o que é Educação Ambiental?

Fig. 4: Educação Ambiental e Complexidade.

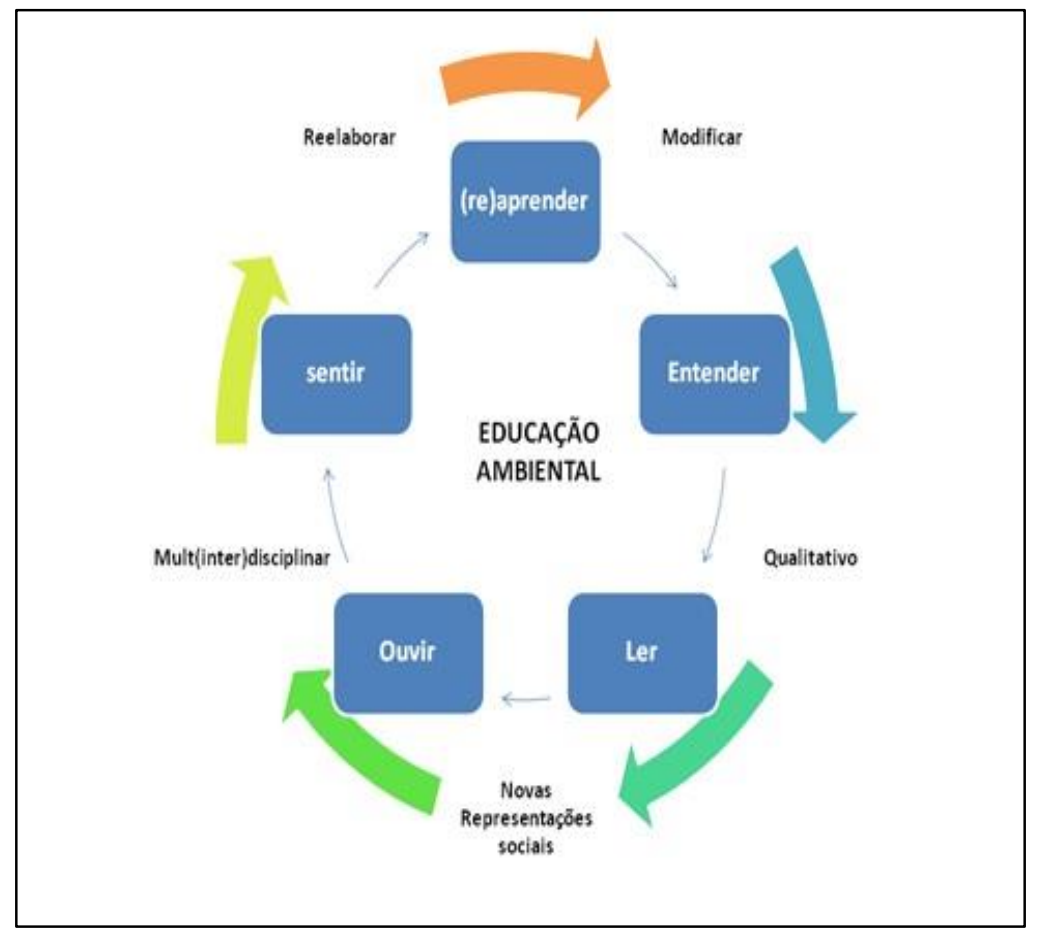

Revista do Instituto Histórico e Geográfico do Pará (IHGP), (ISSN: 2359-0831 - on line), Belém, v. 08, n. 01, p. 19 33, jan.-jun. / 2021. 


\section{DO ENSINO DE GEOGRAFIA E SUAS CATEGORIAS RUMO À EDUCAÇÃO AMBIENTAL (EA)}

Ainda, nos inquieta na literatura voltada para o tema do "ensino de geografia" que essa expressão não se apresente enquanto um conceito, sob o risco de ser considerado definitivamente compreensível, o que venha ser esse ato. Assim, embasados numa proximidade que nos apresenta Paulo(2016): “[...] o ensino de geografia tem o papel primordial: corroborar a compreensão da construção do espaço geográfico e relacionar as interações quanto às questões sociais, culturais, políticas, econômicas e ambientais, ou seja, a organização" (PAULO, 2016, p.27).

Assim, abrangendo 02 (duas) turmas atendidas, totalizando 35 sujeitos pesquisados, a primeira pergunta de uma sondagem, realizada aluno a aluno, a cada início de semestre da disciplina de EA, onde foi realizado o seguinte questionamento: por que da escolha do curso de Geografia? Quase $90 \%$ do universo pesquisado não escolheu a Geografia como primeira opção de curso, corroborando com aquilo que é questionado por Castrogiovani (2000, p.17) sobre “Por que a geografia pode não ser tão interessante?" e, numa de suas justificativas, este autor referenda que o problema estaria na base de formação dos professores das séries iniciais que "não foram alfabetizados em Geografia".

Por essa razão, propor e refletir o ensino de geografia nos cursos de Licenciatura de Pedagogia e Geografia se faz necessário, pois, no âmbito da Geografia, o termo "Ensino", assim como outros conceitos desta área do conhecimento nos remete a uma falsa ideia de cristalização desse objeto. Logo, retoma a reflexão que nos direciona à seguinte trilha de raciocínio: o que é ensino? Educação? Educação ambiental? Enquanto conceitos e, posteriormente, o ato de fazer relação destes com a Geografia, nos parece ainda imprescindível. Ao tratarmos do tema da "água" na disciplina de EA, esta no permite não somente pelo seu caráter transversal, ligado ao meio ambiente, previstos desde os PCN's para o nível fundamental e médio, os quais surgiram em 1998, mas à própria característica para a promoção, voltada para EA, o qual é intrínseco nesta temática.

Assumindo os RH's, enquanto instrumento de ensino e considerarmos que isso nos exige também uma abordagem, uma compreensão e uma intervenção, (inter) multidisciplinar. Esse modo de ver nos concede um conjunto de possibilidades para tratar do tema, sob os mais variados contextos e aplicabilidades. Por essa razão, os recursos hídricos (RH's) tem sido eixo de abordagem desse trabalho.

Em se tratando de Geografia, há uma grande lacuna nesta ciência sob seu casamento com o tema dos RH's, denotando para quem pesquisa uma grande dificuldade em associá-lo com suas categorias específicas de análise, embora alguns autores tenham realizado com certo sucesso, como Bordalo (2006), Ribeiro(2008), Tozi (2009) e Guedes (2016). Todavia, nesse universo, poucos conseguem o debruçar necessário para fazer as devidas análises e amarrações. Contudo, estes trabalhos adotam as categorias geográficas "Território"\&"Paisagem", como as apresentadas aos alunos para as suas reflexões.

Assim, adotamos o território como "aquele que se forma a partir do espaço, o qual é o resultado de uma ação, conduzida por um ator sintagmático (ator que realiza um programa), em qualquer nível" (Raffestin, 1993, p.144). Neste contexto, o Território vem a ser a materialização das possibilidades possíveis 
no espaço que, ao ser produzido, é dotado de conhecimento (a informação apurada) e prática ou comportamentos (a ação propriamente dita), cuja produção do espaço ao território é fruto de um conjunto de relações sociais, inclusive as de poder, os quais tornam o território possível.

Já a concepção da categoria geográfica Paisagem foi a da concepção de Geoges C. Betrand, trabalhada com os discentes, na qual se define como sendo: "uma determinada porção do espaço, o resultado da combinação dinâmica, portanto instável, de elementos físicos, biológicos e antrópicos que, reagindo dialeticamente uns sobre os outros, fazem da paisagem um conjunto único e indissociável, em perpétua evolução".(Bertrand, 1967apud Passos 2007, p.8). Essa concepção de paisagem dá ao aluno o caráter integrador, sistêmico e dinâmico da paisagem, não a vendo como um todo estático e fragmentado do todo.

Noutro aspecto, tratar do tema "água", sob uma perspectiva da realidade local, também tem se mostrado um desafio e, por muitas vezes, inovador, uma vez que fazer uma geografia para além da sala de aula, inserido num ambiente altamente urbanizado, o qual é o contexto das IES aqui envolvidas nesta pesquisa, tem se mostrado de frágil aplicabilidade pelos alunos da teoria versus prática dentro de um contexto de Amazônia com suas especificidades locais.

Justamente porque a Geografia "das salas de aulas" está meramente teóricas e descritivas, numa distorção da etimologia da palavra "Geografia". Tal como no provocam Gebran (1990 apud STRAFORINI, 2008, p. 67) a essa reflexão, "ao trabalhar diretamente com professores em sala de aula, verificou que eles partem sempre da leitura de texto de um livro didático, sendo raras as aulas que se iniciam com leitura de um jornal ou revista. Quando fazem uso da realidade dos alunos, limita-se a descrevê-la".

De fato, revelando inclusive uma incoerência entre a realidade e seu objeto local, a abstração do mundo não cabe dentro dos limites de quatro paredes de uma sala de aula, sob o risco de uma falsa realidade, quiçá a geografia. O que este mesmo autor corrobora é que: "há incoerência entre o modo de ensinar e o movimento de viver a sociedade, incoerente esta apresentada pelo fato de os professores ensinarem conteúdos pretensamente neutros que acabam mascarando a realidade". (Gebran, 1990 apud STRAFORINI 2008.op. cit.)

Nosso ponto de diretriz é o entendimento de Cavalcanti(2017, p.67),onde afirma que "o ensino é a construção de conhecimento pelo aluno" e, dessa forma, ratificamos junto à autora quando trata que o "O aluno é sujeito ativo do seu processo de formação e de desenvolvimento intelectual, afetivo e social, O professor tem o papel de mediador do processo de formação do aluno" e, por essa razão, é preciso tirá-lo da sala de aula e levá-lo à sua própria realidade local, para que essa mediação seja entre o teórico versus a realidade.

\section{A ETAPA DO PLANEJAMENTO: CONVERGINDO AS EMENTAS}

Umas das provocações presentes na bibliografia que trata o ensino de Geografia, especialmente nos cursos de Graduação é o que se refere aos conteúdos lançados aos alunos como vital na construção do saber. 
Logo, no contexto deste trabalho, a variável "planejamento" de determinada disciplina é fundamental, no dizeres de Jacks Paulo: "No entanto, muito se vem discutindo sobre uma formação de professores em que conhecimentos são repassados como algo mecânico, priorizando a memorização de informações, que são produzidas nos mesmos moldes nas avaliações" (PAULO, 2016, p. 7).

Este autor ainda corrobora que "vários estudos sobre teorias do ensino e aprendizagem de Geografia vêm pontuando que, no contexto atual, mesmo com intensas transformações nas formas de representar e de interpretar fatos e fenômenos geográficos, há influência de concepções que não atendem as demandas da contemporaneidade" (ibidem,2016,p.7).

Aplicando ao meio acadêmico e embasado em Straforini (2012), "acreditamos que uma disciplina escolar só se sustenta e toma corpo quando ela se fundamenta teórica-metodologicamente e epistemologicamente na própria disciplina e nas teorias educacionais, ou seja, na psicologia da aprendizagem e do desenvolvimento" (STRAFORINI, 2008 p.78).

Um documento norteador na etapa de planejamento dos cursos superiores de licenciatura é o chamado Projeto Pedagógico de Curso (PPC's), pois, contemplam toda a orientação e especificidades previstas nas chamadas Diretrizes Curriculares Nacionais, logo, todo o "desenho" de cada curso deve estar contido de forma sistemática nesse registro, inclusive as ementas de todas as disciplinas a serem ministradas, de modo a orientar o Professor nessa etapa do "planejamento" de cada disciplina manifestado no seu plano de ensino ou plano de curso, inserido numa única perspectiva de um Projeto, executado nas duas turmas.

Tabela 1: Comparativo temático com base numa abordagem geográfica

\begin{tabular}{|c|c|c|c|c|}
\hline & $\begin{array}{c}\text { LICENCIATURA } \\
\text { EM } \\
\text { PEDAGOGIA }\end{array}$ & $\begin{array}{l}\text { LICENCIATURA EM } \\
\text { GEOGRAFIA }\end{array}$ & COMPARATIVO & ADEQUAÇÕES \\
\hline I. & $\begin{array}{c}\text { Noções Básicas } \\
\text { para a questão } \\
\text { ambiental }\end{array}$ & $\begin{array}{c}\text { Trajetória da Educação } \\
\text { Ambiental. }\end{array}$ & Similaridade & $\begin{array}{l}\text { Conferências; } \\
\text { Conceitos. }\end{array}$ \\
\hline II. & $\begin{array}{l}\text { Meio ambiente e } \\
\text { seus elementos }\end{array}$ & $\begin{array}{c}\text { Metodologias de } \\
\text { educação ambiental } \\
\text { Metodologias de } \\
\text { educação ambiental. }\end{array}$ & Comum & Rios, água. \\
\hline III. & $\begin{array}{c}\text { Os ciclos da } \\
\text { natureza }\end{array}$ & \multirow{3}{*}{$\begin{array}{l}\text { Metodologias de } \\
\text { educação ambiental. }\end{array}$} & Comum & Ciclo Hidrológico \\
\hline IV. & $\begin{array}{c}\text { Sociedade e meio } \\
\text { ambiente }\end{array}$ & & Comum & Território/Paisagem \\
\hline V. & $\begin{array}{l}\text { A contribuição da } \\
\text { Educação } \\
\text { Ambiental para a } \\
\text { conservação dos } \\
\text { recursos naturais } \\
\text { rumo ao } \\
\text { desenvolvimento } \\
\text { sustentável } \\
\end{array}$ & & Comum & $\begin{array}{l}\text { Sustentabilidade e } \\
\text { Desenvolvimento } \\
\text { sustentável }\end{array}$ \\
\hline VI. & $\begin{array}{c}\text { Organização } \\
\text { didática da } \\
\text { educação } \\
\text { ambiental formal e } \\
\text { informal. }\end{array}$ & $\begin{array}{l}\text { Correntes teóricas da } \\
\text { educação ambiental. }\end{array}$ & Similaridade & $\begin{array}{c}\text { E.A enquanto } \\
\text { Representação Social }\end{array}$ \\
\hline
\end{tabular}

Revista do Instituto Histórico e Geográfico do Pará (IHGP), (ISSN: 2359-0831 - on line), Belém, v. 08, n. 01, p. 19 33, jan.-jun. / 2021. 

fomento ao ensino de geografia

\begin{tabular}{|c|c|c|c|c|}
\hline VII. & $\begin{array}{c}\text { A formação } \\
\text { profissional e } \\
\text { docente em } \\
\text { educação } \\
\text { ambiental }\end{array}$ & $\begin{array}{c}\text { Educação ambiental em } \\
\text { ambientes escolares e não } \\
\text { escolares. }\end{array}$ & Similardade & $\begin{array}{c}\text { E.A enquanto } \\
\text { Representação Social }\end{array}$ \\
\hline VIII. & $\begin{array}{c}\text { Legislação e } \\
\text { características da } \\
\text { educação ambiental. }\end{array}$ & Comum & Lei 9.433/97 \\
\hline IX. & $\begin{array}{c}\text { Contribuições da } \\
\text { educação } \\
\text { ambiental para a } \\
\text { segurança e saúde } \\
\text { ambiental e } \\
\text { humana }\end{array}$ & Não Comum & ---- \\
\hline
\end{tabular}

Fonte: o autor

Assim, fazendo um comparativo entre os dois ementários presentes nos Projetos Pedagógicos de Curso (PPC's) dos dois cursos envolvidos nesta investigação, aqui destacamos três (03) elementos por nós denominados de: I- Comuns; II - Similaridade e II- Não Comum, a proximidade destes com a ciência geográfica. Assim, foi gerado no mesmo Quadro 1 uma terceira coluna denominada "adequações" relacionados aos conteúdos que pela sua "similaridade" ou aspectos "comuns" puderam gerar conteúdos as serem trabalhados adequadamente nos dois cursos. Essa perspectiva vai ao encontro as inquietações levantadas por Lana Cavalcanti (2017, p. 66), pois, no ato de planejar estas perguntas devem ser fazer presentes na mente de cada professor:

a) O que é a Geografia Escolar na atualidade? b) Como ela se realiza? c) Como o Professor constrói? d) Quais os desafios na prática do ensino da Geografia? e) Quem são os alunos da Geografia? f) Como são esses alunos? g) Que significados têm para esses alunos aprender Geografia? h) Que dificuldades eles têm em aprender os conteúdos trabalhados nessa disciplina? (CAVALCANTI, 2017, p. 66).

A partir desse procedimento, tornou possível o "planejamento" da disciplina de Educação Ambiental para duas turmas de cursos diferentes (Pedagogia e Geografia), de modo que as aulas presenciais, suas atividades, oficinas, palestras, bem como o trabalho de campo, pudessem ter destinos, atividades, abordagens e solicitação de um mesmo produto comum - o relatório e, para efeito comparativo deste trabalho, tudo.

Embora alguns dos livros e textos servem com base ao referencial teórico deste trabalho, outrossim, o fator comparativo presente no Quadro 1, mencionado a seguir, houve uma grande implicação, inclusive na escolha dos conteúdos e de qual bibliografia trabalhada deveria ser adotado nos dois cursos. Todavia, neste trabalho são destacadas no referencial bibliográfico somente as obras comuns nas duas disciplinas, sendo apresentados aqueles livros ou artigos que foram comuns nas coletâneas de textos dos dois cursos disponibilizados aos discentes, aqui organizado, segundo as suas abordagens centrais como forma, de mostrar como a convergência geográfica para a abordagem ambiental perpassou o planejamento das disciplinas, inclusive como algo sistematicamente necessário na etapa do planejamento das aulas. 
Preocupou-se com arranjo dos temas abordados (Fig.5), onde, analisando num sentido centrífugo a cada momento (Nível) do esquema, denota o conjunto de afinidades entre os temas tratados: Nível 1 Geografia; Nível II - os eixos transversais trabalhados e o Nível III (mais externo) a amplitude do tema água, ao mesmo tempo em que revela a matriz geográfica e pedagógica e a forma como fora tratada, o qual auxiliou na compreensão do referencial teórico adotado.

Fig. 5- Níveis I, II e III de temáticas desenvolvidas nas disciplinas

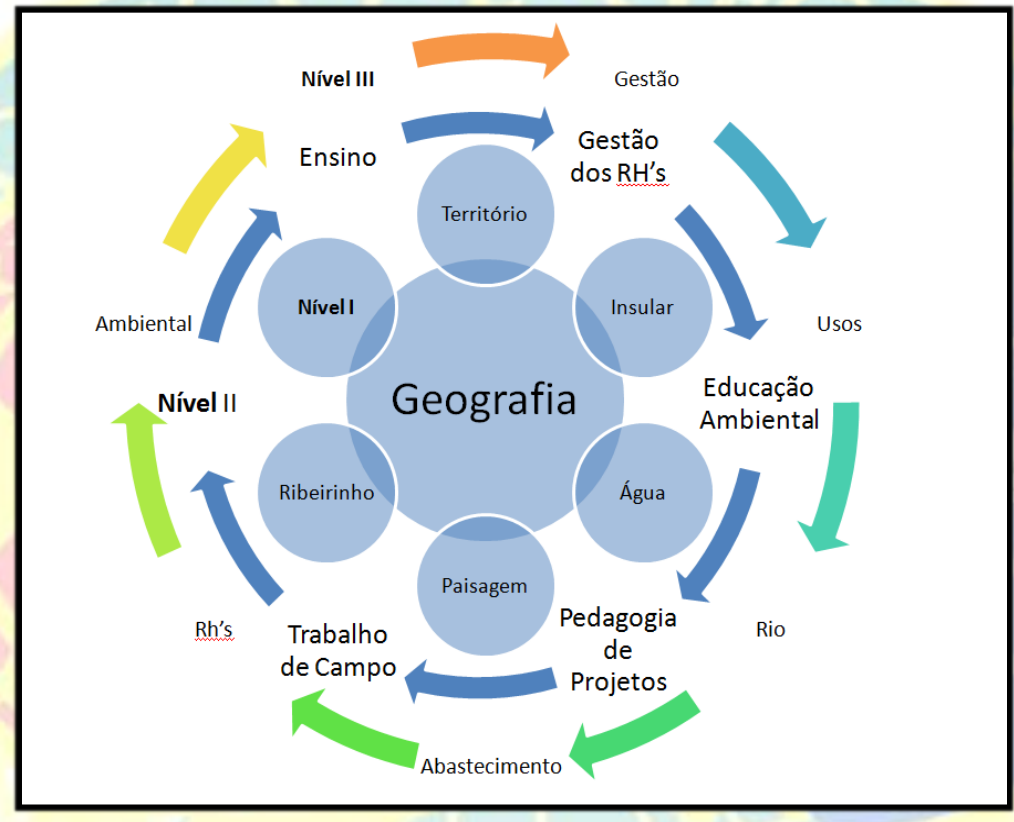

\section{DOS DADOS E DO RELATÓRIO}

Considerando os relatórios e analisando os temas/títulos e os conteúdos, desenvolvidos livremente pelos próprios alunos, cuja orientação era de que fossem relacionados com a disciplina de Educação Ambiental e a Geografia, dentro dos 10 relatórios da turma de Licenciatura em Geografia, foram extraídos apenas 4(quatro) que optaram por desenvolverem temas da "relação da geografia versus a educação ambiental ou recursos hídricos". Todavia, os 10 relatórios desta turma trabalharam de algum modo a dimensão local. Porém, a turma de Licenciatura em Pedagogia foi a que, na sua totalidade dos 12 relatórios apresentados, escolheram e desenvolveram temas que apontassem essa relação simplificada, conforme é apresentada na Tabela 2:

Tabela 2: Grupos temáticos/conteúdos, trabalhados pelos alunos. Fonte: o autor.

\begin{tabular}{|r|c|c|c|}
\hline & GRUPOS TEMÁTICOS & LIC. GEOGRAFIA & LIC. PEDAOGIA \\
\hline I & $\begin{array}{c}\text { Relação Geografia versus } \\
\text { Educação ambiental ou RH's }\end{array}$ & $\mathbf{4 ( + )}$ e 6(-) & 12 \\
\hline II & Relação com o Local & $\mathbf{1 0}(+)$ & 12 \\
\hline II & Relação com outra disciplina & & 10 \\
\hline
\end{tabular}




\section{CONSIDERAÇÕES FINAIS}

A capacidade de extrapolar os muros da sala de aula no universo acadêmico constitui-se numa ação, o qual é muito importante no fazer cotidiano do Professor, nesse conjunto de relações, entre eles, a sua disciplina. A possibilidade de planejamento de uma disciplina que possa agregar outras práticas, conhecimentos saberes e ciências tende a ampliar o horizonte e as concepções dos sujeitos que, muitas vezes, direta ou indiretamente, se tornarão meros reprodutores das práticas e metodologias vivenciadas em seu processo formativo.

A proposta presente em volta da Pedagogia dos Projetos, quando adotado e praticado, tende a movimentar a escola, a universidade a comunidade, pois, desde a sua concepção, o poder, que têm um Projeto enquanto ganho em parte do processo educativo do sujeito, não cabe em algumas laudas escritas. Essa eficiência que é trabalhar a Educação Ambiental, a partir da integração com outras disciplinas traz possibilidades ao aluno, no início de uma leitura sistêmica dos fenômenos naturais do mundo. Ensinar Geografia, esse ato em si, ainda preso na velha dicotomia que parece não caducar e a limitação imposta pelas suas categorias ou "caixinhas", muitas vezes, limita a nós mesmos como professores.

A dimensão geográfica foi provocada a partir da discussão do tema dos recursos hídricos, associado à categoria Território e Paisagem, voltadas para uma comparação entre o ambiente urbano e rural, num contexto amazônico em que permearam essas duas realidades apresentadas e discutidas neste trabalho com os discentes, além do caráter intrínseco aos cursos aqui trabalhados.

Por serem de Licenciatura, a dimensão do ensino foi amplamente considerada no teor das reflexões no interior da disciplina de EA, uma vez que a intenção maior foi provocar nos alunos a ideia do aprender a fazer como contribuinte no seu processo formativo. Dos vinte e dois relatórios analisados, tanto da turma de Geografia quanto o de Pedagogia, constatou-se que os sujeitos num primeiro momento antes da disciplina de Educação Ambiental nem sempre se perceberam integrantes do espaço amazônico, tampouco sua relação com a água em seus usos e dimensões.

Neste contexto, o rio, a paisagem, a natureza, o sujeito ribeirinho, muitas vezes, sãos negados dentro da própria relação de identidade destes discentes, uma vez que, ao irem ao campo, eles vislumbraram como algo absoluto, chegando a ser absurdamente novo, uma vez que o rio Guamá é elemento geográfico que separa a cidade de Belém e toda a porção insular da Ilha do Combú, o qual compreende $65 \%$ do seu território, o que leva apenas 20 minutos de travessia de embarcação, corroborando com o que alguns autores se referem sobre esse estado de negação, onde "a cidade de Belém foi construída de costas para o rio".

\section{REFERÊNCIAS}

BORDALO, Carlos Alexandre Leão; TRINDADE, Andreza Barbosa; SOUSA, Elivelton dos Santos; GUEDES, Michel Pacheco. O paradoxo da água na Amazônia. IN: Christian (org). Produção do espaço e territorialidade na Amazônia paraense: elementos para análise geográfica. Belém: Ed. GAPTA UFPA, 2016. 
CAVALCANTI, Lana de Souza. Ensino de Geografia e diversidade: construção de conhecimentos geográficos escolares e atribuição de significados pelos diversos sujeitos do processo de ensino. IN: CASTELLAR. Sonia. Educação Geográfica: teorias e práticas docentes. São Paulo: Ed. Contexto, 2005.pp 66-78.

CAVALCANTI, Lana de Souza; CASTELLAR, Sônia (Org). Educação geográfica: Teorias e práticas docentes. In: Construção de conhecimentos geográficos escolares e atribuição de significados pelos diversos sujeitos do processo de ensino. $3^{\mathrm{a}}$ Edição. $2^{\mathrm{a}}$ Reimpressão. São Paulo: Contexto, 2012. pp. 66-78.

CASTROGIOVANI, Antonio Carlos (Org.). Ensino de Geografia. Porto Alegre: Ed. Mediação, 2000.144p.

GUERRA, Gutemberg Armando Diniz. Eidorfe Moreira e o aspecto insular de Belém. Bol. Mus. Para. Emílio Goeldi. Ciênc. hum. vol.10 no.3 Belém Oct./Dec. 2015. Disponível em: https://www.scielo.br/scielo.php?script=sci_arttext\&pid=S1981-81222015000300583. Acesso em: $21 \mathrm{de}$ outubro de 2020.

LOUREIRO, Carlos Frederico B. Sustentabilidade e educação: uma olhar da ecologia política. São Paulo: Ed. Cortez, 2012. 128p.

NEVES, Karina Fernanda Travagim Viturino. Os trabalhos de campo no ensino de geografia: reflexões sobre a prática docente na educação básica. Ilhéus: Editus, 2010. 137p.

NOGUEIRA, Nilbo. Pedagogia dos Projetos. $7^{a}$ edição. São Paulo: Ed. Saraiva, 2007. 200p.

ONÇA, Daniela de Souza. A função Social dos Discursos Ambientalista. VII Colóquio Internacional Marx Engels, 2012. Disponível em: https://www.ifch.unicamp.br/formulario_cemarx/selecao/2012/trabalhos/6059_On\%C3\%A7a_Daniela.pdf.

Acesso em: 21 de outubro de 2020.

PAULO, Jacks Richard de. A formação de professores de Geografia: contribuições para mudança de concepção de ensino. Jundiaí: Ed. Paco editorial, 2016. 64p.

RIBEIRO. Wagner da Costa. Geografia Política da Água. São Paulo: Ed. Annablume, 2008. p. 13-52.

RAFFESTIN, C. Por uma Geografia do Poder. Tradução de Maria Cecília França. São Paulo: Ática, 1993.

REIGOTA. Marcos. Meio Ambiente e representação social. $8^{a}$ Edição. São Paulo: Ed. Cortez, 2010. 96p. SANTOS, Elizabeth da Conceição. Geografia, Educação Ambiental e os novos paradigmas. In: Geografia e educação ambiental: reflexões epistemológicas. Ed. EDUA, Manaus, 2009. 278p.

STRAFORINI, Rafael. Ensinar Geografia: o desafio da totalidade-mundo nas séries iniciais. $2^{\text {a }}$ Ed. São Paulo: Ed. Annablume, 2004. 190p.

TOZY, Shirley Capela. Bacia hidrográfica: aspectos teóricos e conceituais da teoria de sistemas ao Geossistema. In: Caminhos e Lugares da Amazônia: ciência, natureza e território. Belém: GAPTA/UFPA, 2009.pp. 195-206. 